\title{
ESTUDO DAS COMPETÊNCIAS: PROFISSIONAIS DA SAÚDE
}

DOI: $10.22289 / 2446-922 X . V 2 E E A 3$

Mariana Martins Ramos

Constance Rezende Bonvicini ${ }^{3}$

\section{RESUMO}

As exigências do mercado de trabalho têm se tornado cada vez mais específicas e o profissional precisa desenvolver cada vez mais suas competências. O presente estudo foi realizado a partir de uma revisão bibliográfica com o intuito de caracterizar o comportamento competente no ambiente de trabalho, identificando questões que envolvem os profissionais da área de saúde. Evidenciando-se as dificuldades encontradas em lidar com adversidades em sua prática profissional. Os resultados do estudo apontam sobre a necessidade da revisão da formação acadêmica dos profissionais da saúde e da divulgação de informações sobre estratégias que favoreçam a qualidade de vida. Foca-se na atuação do profissional psicólogo competente dentro da área da saúde e como ele pode fomentar projetos que encorajam o desenvolvimento de uma cultura de gestão baseada em evidências e sobre a necessidade do desenvolvimento de metodologias de construção do conhecimento e da aprendizagem organizacional.

Palavras chaves: Psicólogo e prática; Competência; Gestão de saúde.

\section{ABSTRACT}

The demands of the labor market has become increasingly specific and professional needs to develop more and more their skills. This study was conducted from a literature review in order to characterize the appropriate behavior in the workplace, identifying issues involving health professionals. Highlighting the difficulties encountered in dealing with adversity in their professional practice. The study results point to the need to review the academic training of health professionals and the dissemination of information on strategies that enhance the quality of life. It focuses on the role of the competent professional psychologist in the area of health and how it can promote projects that encourage the development of an evidence-based management culture and the need to develop construction methods knowledge and organizational learning.

Key words: Psychologist and practice; Competence; health management.

\section{INTRODUÇÃO}

Perante o contexto atual, torna-se necessário o aprofundamento de estudos na área que investiga como se comportam os profissionais da área de saúde, em organizações que

\footnotetext{
${ }^{3}$ Endereço eletrônico de contato: constancebonvicini@yahoo.com.br
}

Outubro, 2016:2(Edição Especial):28-40. 
exijam uma postura competente dos profissionais que atuam ou desejam atuar nessas, agregando para os que estão a sua volta e para a própria organização.

O indivíduo pode gerar benefícios para o ambiente de trabalho, se comportando de maneira competente e socialmente assertiva, para alcançar objetivos dentro e fora da organização, obtendo então destaque em organizações do trabalho e agregando valor a empresa. Nesse contexto, o psicólogo pode participar ativamente identificando e desenvolvendo competências dos indivíduos nas organizações de trabalho.

A competência é vista como um conjunto de conhecimentos, habilidades e atitudes que formam um grande desempenho, qualidade de ser adequado e bem qualificado física ou intelectualmente para grandes ou pequenos desafios no trabalho. É a capacidade de tomar decisões bem informadas e coerentes. ${ }^{(1)}$

Acrescenta ainda ao construto competência as variáveis relacionadas à aprendizagem, na medida em que situa a capacidade num ponto convergente entre a pessoa, sua formação educacional e sua experiência profissional.(2)

Compreendendo-se sobre a aplicação da noção de competências em situações organizacionais. ${ }^{(3)}$ o estudo mostra que [...] "as competências são entendidas como a ação que combina e mobiliza as capacidades e os recursos tangíveis (quando for o caso)." As capacidades, por sua vez, seriam potenciais (conhecimentos, habilidades e atitudes) de competências que estão disponíveis para serem mobilizadas em um momento específico.(3) Quando se alinham pensamentos, na relação indivíduo e organização, as competências compreendem a soma dos conhecimentos presentes nas habilidades individuais e nas unidades organizacionais. ${ }^{(4)}$

Assim, competência enquanto aspecto relevante do conhecimento, como aprendizado e destreza em realizar e discernir torna-se a essencialidade do fazer. Neste sentido, o exercício das profissões acompanha as necessidades que perpassam as demandas da sociedade, que se demonstra cada vez mais exigente, tanto na interação pessoal, quanto na formação especializada. ${ }^{(5)}$

A competência se relaciona com capacidade do indivíduo de assumir iniciativas, estar além do prescrito, compreender e dominar situações em constante mutação, ser responsável e reconhecido por outros. A percepção desse autor deriva de basicamente três pontos: a natureza contingencial do mundo moderno, o teor participativo da comunicação intraorganizacional e seus impactos na visão de serviços dentro e fora das organizações. ${ }^{(1)}$

A competência associa-se a capacidade de resolução de tarefas e de comunicação, saberes técnicos, modo de fazer enquanto habilidade na realização e saber ser enquanto conjunto de comportamentos e atitudes úteis para empresa. As empresas estão cada vez mais interessadas em desenvolver pessoas que saibam usar sua habilidade e toda sua

Outubro, 2016:2(Edição Especial):28-40. 
competência, não adiantando só ter carisma, conhecimento, diplomas e mais diplomas se o indivíduo não tem a capacidade de colocar em prática tudo àquilo que aprendeu durante toda sua vida, pois hoje em dia o dito popular 'Quem não tem competência não se estabelece'.(6)

Essas duas características, habilidade e competência, têm uma conotação muito abrangente se comparadas com seus significados em tempos passados. Com a chegada da informática e com o crescimento assustador da concorrência, essas duas características precisam ser mais do que nunca aprimoradas por todo aquele profissional que deseja progredir e obter sucesso. ${ }^{(7)}$

Quando se trata da gestão por competência, uma de suas características é realizar a gestão e o desenvolvimento de seus recursos humanos de acordo com a capacitação de seus colaboradores, apontando a competência prevista de cada cargo, podendo também investir no funcionário em seu alto desenvolvimento, na medida em que ele obtém níveis maiores de competência dentro do cargo. ${ }^{(6)}$

Se a empresa possui foco na gestão por competência, nota-se que as ações e comportamentos identificados pela liderança são de efetivas contribuições para a mudança. O planejamento estratégico é fundamental para a ligação com a função exercida, pois este busca integração dos seus objetivos, estes comportamentos são necessários para um desempenho satisfatório ou excelente em qualquer desafio profissional. ${ }^{(8)}$

Desta forma, para a palavra competência, sugerem-se muitas interpretações, dependendo do contexto em que é usada. Competência pode representar: autoridade, quando significa o poder que se encontra na direção organizacional; capacitação, quando significa o saber fazer e o saber conhecer do indivíduo; competição, quando estabelece as metas a serem alcançadas, gerando rivalidade; qualificação, quando no recrutamento e seleção. Na área de Gestão de Pessoas, psicólogos do trabalho apontam candidatos aptos, ou não, para o cargo, uma referência à capacidade que a pessoa tem de lidar com os próprios problemas e resolvê-los de uma maneira mais efetiva. ${ }^{(9)}$

$\mathrm{Na}$ gestão de equipes de saúde, em que os sentimentos e superação das barreiras emocionais se fazem necessários, as principais dificuldades de gestão do trabalho coletivo em saúde dizem respeito: à relação entre sujeitos individuais e coletivos; à história das profissões de saúde e o seu exercício no cenário do trabalho coletivo institucionalizado e à complexidade do jogo político e econômico que delimita o cenário das situações de trabalho. ${ }^{(10)}$

O papel do profissional da psicologia se amplia para além do paciente, abrangendo, com isso, a dor da família. Assim, além do trabalho realizado em torno da doença, da internação e do tratamento do paciente, há o apoio à família e, também, à equipe médica.(10)

Outubro, 2016:2(Edição Especial):28-40. 
Esta pesquisa se propõe, portanto, a caracterizar o comportamento competente no ambiente de trabalho, identificando os profissionais de saúde diante da qualidade de vida perante o enfrentamento do dia a dia.

\section{METODOLOGIA}

O presente trabalho foi realizado através de pesquisa bibliográfica com a utilização de dissertações, artigos e livros, utilizando obras publicadas em português e inglês no período de 1973 a 2015. As palavras-chave utilizadas para a busca foram: Psicólogo e prática. Competência. Gestão de saúde.

\section{A ABORDAGEM DAS COMPETÊNCIAS}

Competência é vista como um conjunto de conhecimentos, habilidades e atitudes que formam um grande desempenho. É a capacidade de tomar decisões bem informadas e coerentes. ${ }^{(1)}$

Ao se abordar o tema competência, logo se remete a uma qualificação interna do sujeito. Ser competente ou incompetente é uma característica da personalidade do sujeito.(11)

Esse modo de classificação por si só já traz alguns constrangimentos as mais antigas noções sobre o estudo das competências, que são considerados conceito dinâmico, que se referem a um saber fazer que dependa de várias variáveis para se executar uma tarefa, o que envolve condições promovidas para que a mesma seja executada. ${ }^{(6)}$

A competência era uma característica subjacente a um indivíduo, eventualmente relacionada com o desempenho superior na realização de uma tarefa ou em uma situação particular. Com esse pensamento se distinguiu o conceito de competência de aptidão, habilidade e conhecimento. Aptidão é o talento que nasce o indivíduo, habilidade é um talento particular demonstrado na prática e conhecimento é o que se tem de saber para desempenhar uma tarefa. ${ }^{(12)}$

As pesquisas de campo realizadas sobre as competências começaram a progredir na década de 80 , quando houve maiores estudos que possibilitaram o recolhimento de dados em que foi possível observar alguns traços característicos que justificaram o desempenho anterior. Estes traços formavam a sigla C.H.A.: conhecimento, habilidade e atitude. ${ }^{(2)}$

A partir dessas informações, as empresas passaram a investir muito na qualificação de sua mão de obra, atrelando competência as funções. ${ }^{(1)}$ Completando essa idéia, pode-se definir a competência é o conjunto de conhecimentos sociais e de comunicação adquiridos, é

Outubro, 2016:2(Edição Especial):28-40. 
o saber agir responsável que significa ter capacidade de mobilizar, integrar e transferir os conhecimentos, recursos e habilidades no âmbito profissional. ${ }^{(12)}$

Durante muito tempo ter uma profissão era o objetivo essencial do ser humano na idade adulta. Se garantir com um emprego a partir de uma formação universitária era algo que garantia estabilidade para aqueles que dedicaram boa parte da vida aos estudos. A competência focada no ramo profissional diz respeito ao que as empresas buscam e precisam, elas estão diretamente voltadas para 0 atendimento das necessidades organizacionais, beneficiando quem se apresentar melhor. ${ }^{(11)}$

Atualmente, ao se abordar o tema competência, é necessário observar suas principais características que são a transformação de conhecimentos, aptidões, habilidades, interesse, vontade, entre outros. Quando se fala em transformação leva-se o conceito de competência a uma mobilidade e uma abertura que não se via nos conceitos de qualificação de mão de obra. É necessário que se entenda competência como a capacidade de mobilizar saberes para agir em situações reais de trabalho.

A competência não seria um estado de formação educacional ou profissional, nem tampouco um conjunto de conhecimentos adquiridos ou de capacidades apreendidas, mas seria a mobilização e aplicação de conhecimentos e capacidades numa situação específica, na qual se apresentam recursos e restrições próprias à sua especificidade. ${ }^{(13)}$

A qualificação sobressai às competências adquiridas por um indivíduo, seja por formação ou pela execução de suas atividades com a utilização desses recursos na prática. Em outras palavras, é um novo tipo de qualificação. ${ }^{(1)}$

O enfoque das competências está centrado nos indivíduos que conseguem aprender, ao se depararem de forma reflexiva com situações reais e as reconstroem por sua iniciativa, demonstrando responsabilidade pelo seu trabalho e a seu próximo.(14)

O quadro 1 aponta conceitos e competências. As definições citadas esclarecem que existem três dimensões da competência, o saber, o fazer e o saber ser. Desse modo entende-se que ser competente é uma consequência da utilização adequada pelo indivíduo de seus atributos competentes.

Desta forma, a definição de competência profissional associa-se ao verbo ação, isto é, o desenvolvimento de uma ação baseada em conhecimento, desenvolvidas conforme a necessidade do profissional para aumentar seu desempenho em suas atividades. ${ }^{(15)}$

Por outro lado, o comportamento no trabalho exige do profissional além do conhecimento, suas habilidades e também suas atitudes perante a função e aos demais. Para compreensão de atitudes individuais necessita-se a compreensão do ambiente em que se está inserido, assim fala-se na cultura e suas características. ${ }^{(15)}$

Outubro, 2016:2(Edição Especial):28-40. 


\section{Conceitos e Competên cias}

\begin{tabular}{|l|l|}
\hline Conceito & $\begin{array}{l}\text { Definição } \\
\text { Conjunto de informações obtido por } \\
\text { meio de leitura que possibilitam ao } \\
\text { profissional o domínio do saber e a } \\
\text { capacidade de tomar decisões e } \\
\text { solucionar problemas. } \\
\text { Habilidades }\end{array} \mid \begin{array}{l}\text { Conjunto de experiências obtidas por } \\
\text { repetições que fornecem ao } \\
\text { profissional a capacidade do saber } \\
\text { fazer e de tomar decisões para a } \\
\text { solução de problemas. }\end{array}$ \\
\hline
\end{tabular}

Quadro 1: Conceitos e competências.

\section{CULTURA ORGANIZACIONAL E O PROFISSIONAL DE SAÚDE}

O indivíduo é composto por um conjunto de valores que são organizados de forma hierarquizada, segundo a sua relevância como: liberdade, honestidade, verdade, justiça, ética, disciplina, integridade, respeito e obediência. ${ }^{(16)}$

Esses mesmos valores ainda podem ser subdivididos segundo a um critério no foco para o qual está centrado, ou seja, na pessoa ou no grupo social.(17) Os valores são universais, pois são requisitos básicos á existência humana, onde todos possuem ação social coordenada, necessidades biológicas, entre outras. Assim, indivíduo expressa necessidades distintas buscando constantemente motivações que o instigue a melhorar tanto no âmbito profissional quanto pessoal. O ser humano como um todo vive em busca da aceitação dentro dos grupos que convivem com o intuito de obter realização profissional e emocional. ${ }^{(18)}$

Especificando-se sobre a Psicologia, que ao ser inserida no hospital passa a desenvolver técnicas, conceitos e questionamentos criando dela uma nova alternativa e apoio Outubro, 2016:2(Edição Especial):28-40. 
na busca da compreensão da existência humana. A Psicologia dentro do hospital tem como premissas principais minimizar no paciente o sofrimento causado pela hospitalização, bem como prevenir futuras seqüelas e implicações emocionais dessa hospitalização, abrangendo a dor da família. ${ }^{(19)}$

Os profissionais da saúde se deparam regularmente com o processo de morte e, muitos deles, não estão preparados para lidar com os impactos emocionais significativos decorrentes desse fenômeno. Nesse sentido, tais profissionais assumem práticas e atitudes de negação da morte, evitando o contato com suas próprias emoções. Os impactos emocionais decorrentes do processo de morte e luto podem produzir sérios prejuízos psicológicos nos profissionais de saúde afetando sua qualidade de vida e bem estar no trabalho. ${ }^{(20,21)}$

Cuidar do outro expõe o profissional da saúde a emoções e sentimentos que revelam os fantasmas de suas próprias realidades de perdas, mortes e lutos relembrando fatos do histórico familiar, medos infantis de separação e de sua própria imortalidade. Os profissionais de saúde apresentam defesas e posturas diante do paciente, sendo essas facilitadoras ou prejudiciais ao tratamento. ${ }^{(22,23)}$

Nos objetivos das principais profissões de saúde não constam a preparação para perdas e lutos, o profissional da saúde é formado para curar ou auxiliar no tratamento doenças e não para lidar com as pessoas. O contato dos promovedores de saúde: médicos, enfermeiros e psicólogos, com esta finitude pode provocar práticas e atitudes que fogem da prática técnica e profissional, impedindo que o processo ocorra de forma natural. (24)

[...] alguns psicólogos quando estão atuando junto ao paciente próximo de morrer evitam criar vínculos intensos, e procuram realizar suas atividades de uma maneira em que dão mais ênfase as suas técnicas, ou seja, mais especificamente a sua atuação, para assim se proteger diante do envolvimento com o sofrimento da morte. ${ }^{(24)}$

Os profissionais percebem as demandas de trabalho como eventos estressores aos quais não suportam, não tem força vital para enfretamento das situações que o agridem. Esta exposição provoca reações físicas, psíquicas e comportamentais podendo tornar se crônico e causar danos às relações interpessoais nas dimensões familiares, sociais e profissionais, em ofensivas frustrações e inadequação, podendo resultar no abandono da profissão. ${ }^{24,25,}$ 29)

Através de estudos de estresse surgiu a Síndrome de Burnout, definida como um fenômeno psicossocial que emerge como uma resposta crônica aos estressores decorrente do trabalho. "Burnout do inglês: burn = queimar, out = fora é um termo que designa algo, ou Outubro, 2016:2(Edição Especial):28-40. 
alguém, que não possui mais energia, chegou ao limite de forças, não funciona mais, queimou até o fim". Burnout consiste em desgaste profissional, facilmente observável em profissionais que trabalham diretamente com pessoas. ${ }^{(25,26)}$

O processo de aprendizagem como uma atividade estruturada, relacionada a cada indivíduo, à medida que eles se preparam para realizar suas atividades e, posteriormente, quando buscam melhorias nas habilidades clínicas. Esse modelo pressupõe uma visão de aprendizagem relacionada ao indivíduo, linear e focada. Nesse contexto, uma das principais formas de aprendizado é pela repetição. Uma vez que o aprendizado ocorre a partir do indivíduo, pela repetição visando chegar às melhores práticas. ${ }^{(27)}$

Os estilos de vida e as relações interpessoais e a satisfação com os estilos de vida, influenciam podendo negativamente gerar a exaustão emocional, sendo que as relações interpessoais também influenciam positivamente a realização pessoal. ${ }^{28,29)}$

A construção da aprendizagem organizacional em empresas do setor de saúde, o processo de reflexão, re-interpretação, refinamento e codificação do conhecimento deve ser realizado por grupos, e não apenas individualmente. Pode-se justificar essa afirmação pela complexidade das instituições de cuidados com a saúde. Além da existência de uma estrutura organizacional complexa, diferentes profissionais atuam com visões diferentes, sobre o mesmo objeto: o paciente. ${ }^{(29)}$

\section{DISCUSSÃO}

Tendo-se em vista que a competência é um conjunto de conhecimentos, habilidades, atitudes que formam um grande desempenho e acrescentando-se ${ }^{(1)}$, e ainda que as competências são variáveis relacionadas ao aprendizado em forma de experiências profissionais ou até mesmo como uma formação educacional(2). Afirma-se que para ser competente em algo, deve-se possuir capacidade de compreender as pessoas, tomar iniciativa de dominar algumas situações de riscos e mudanças que possa enfrentar. Completando tal conceito, pode-se dizer que competência é o conjunto de conhecimentos sociais e de comunicação adquiridos, é o saber agir responsável que significa ter capacidade de mobilizar, integrar e transferir os conhecimentos, recursos e habilidades no âmbito profissional. ${ }^{(12)}$

As competências estão centradas nos indivíduos que se esforçam e conseguem aprender de forma eficaz, ao que se deparar com certas dificuldades saberão como agir demonstrando responsabilidade e comprometimento em seu ambiente de trabalho. Competência seria assim a capacidade de combinar, misturar e integrar recursos em produtos e serviços. ${ }^{(14)}$

Outubro, 2016:2(Edição Especial):28-40. 
Portanto, o comportamento no trabalho exige muito mais que apenas conhecimento e habilidades, precisa também saber fazer as atividades exigidas e se esforçar para aquisição de novos conhecimentos da área, mostrando competência em tudo que faz em seu ambiente de trabalho. A definição de competência profissional associa-se ao verbo ação, onde a prática de uma ação é fundamentada em conhecimento, desenvolvida conforme a necessidade do profissional para melhorar seu desempenho em suas atividades, considerando o ambiente em que o mesmo se encontra. ${ }^{(15)}$ Assim, a competência profissional passa ser a construção do conhecimento com responsabilidade e reconhecimento de todos.

A competência de uma liderança está casualmente relacionada com desempenho superior na realização de uma tarefa ou situação, são líderes competentes que demonstram ações e comportamentos que ajudam no desenvolvimento das empresas, qualificadas e mostrando um desempenho satisfatório ou excelente em qualquer desafio profissional.(31)

A gestão de pessoas é a função que permite a participação efetiva de todos para alcançar os objetivos organizacionais e individuais e é seguida da gestão do conhecimento, pois elas permitem que indivíduos trabalhem juntos desempenhando um papel em uma organização. Atualmente, as organizações trabalham interligando todos os seus setores em busca de um objetivo comum. ${ }^{(30)}$

Os trabalhadores de saúde são sujeitos de processos de trabalho que os aproximam e os afastam da crença de que é possível um novo projeto de atenção à saúde que tenha como referência a integralidade da atenção. E para um novo projeto, é preciso tornar-se um agente de mudanças. ${ }^{(28,29)}$

Assim, o psicólogo é mais que um recrutador e selecionador nas equipes de saúde, ele é visto como um grande estudioso da mente e do comportamento humano tem como facilitar a inter-relação entre os processos de comunicação. Este profissional precisa ter capacidade de ouvir e ter uma excelente comunicação, mostrando incentivos e benefícios. ${ }^{(10)}$

O trabalho em saúde envolve uma relação entre sujeitos que agem nas dramáticas do uso de si e que fazem a gestão do seu próprio trabalho; é influenciado pela história das profissões de saúde e pelas determinações macro-políticas. Conclui-se que essa complexidade do trabalho em saúde precisa ser considerada no processo de gestão de equipes/coletivos profissionais de modo a articular ações que possibilitem implementar um novo projeto de atenção à saúde na perspectiva da integralidade. ${ }^{(28,29)}$

No campo da gestão de equipes, o profissional da saúde deve exercer funções de aceitação, consolidação, manutenção e mudança cultural, procurando realizar a missão de uma empresa, desempenhando um papel primordial no dia a dia de uma organização.(30) Assim, é de suma importância que as competências específicas a essa área estejam 
delimitadas aos objetivos estratégicos da empresa. Ele funciona como um suporte as demais áreas alinhando as competências com a cultura organizacional. ${ }^{(31)}$

\section{CONCLUSÃO}

O indivíduo pode gerar benefícios para o ambiente de trabalho, se comportando de maneira competente e socialmente assertiva, para conseguir seus objetivos dentro ou fora da organização, obtendo então destaque em organizações do trabalho e agregando valor a empresa.

O ser humano considerado como ser competente na realização de suas funções em uma determinada empresa tem como característica principal a pro-atividade e a sua capacidade multiprofissional de trabalhar em grupo. As empresas atualmente estão em busca de colaboradores que consigam desempenhar um trabalho completo que vá além de suas funções específicas, se tornando uma peça chave e participando ativamente do sucesso da empresa para a qual presta serviço. A gestão do conhecimento se torna peça chave para empresa.

A utilização de um sistema de gestão de conhecimento esta diretamente ligada cultura organizacional existente e esta mesma é o que separa as organizações. Olhando desse modo a cultura de uma organização, sendo um sistema de valores e crenças compartilhados que influenciam o comportamento daqueles que o compartilham.

Assim, uma organização é uma junção de esforços singulares que tem por finalidade realizar propósitos coletivos e por meio de uma organização torna-se viável alcançar objetivos que seriam inatingíveis para uma pessoa. Sendo assim pode-se concluir que estabelecer uma boa gestão de pessoas e uma boa gestão de conhecimento é alguns dos requisitos básicos para se ter uma organização de sucesso. Na gestão de equipes de saúde, em que os sentimentos e superação das barreiras emocionais se fazem necessários, principalmente.

Portanto as principais dificuldades de gestão do trabalho coletivo em saúde dizem respeito: à relação entre sujeitos individuais e coletivos; à história das profissões de saúde e o seu exercício no cenário do trabalho coletivo institucionalizado e à complexidade do jogo político e econômico que delimita o cenário das situações de trabalho. O profissional psicólogo nos últimos anos ganhou grande espaço no desempenho de suas funções da saúde, pois neste ramo ele tem tanto o trabalho de recrutamento e seleção como o de gerenciar os mesmos selecionados nas suas funções desempenhadas no hospital e assim como a sua

Outubro, 2016:2(Edição Especial):28-40. 
formação o permite analisando tanto a sua forma profissional como a social, fazendo assim um trabalho completo.

Tais reflexões esclarecem qual o papel do psicólogo em sua atuação, de forma ampla, sendo não só um profissional do âmbito clínico, mas sim um profissional de inúmeras funções, podendo atuar em diversas situações.

\section{REFERÊNCIAS}

1. Zarifian, P. Objetivo competência: por uma nova lógica. São Paulo: Atlas, 2001.

2. Le Boterrf, G. Desenvolvendo a competência dos profissionais. Porto Alegre: Artmed, 2003.

3. Ruas, R. Gestão por competências: uma contribuição à estratégia das organizações. In: Ruas, R. Antonello, C. Boff, H. Os novos horizontes da gestão: aprendizagem organizacional e competências. São Paulo: Bookman; 2005.

4. King, A. Fowler, S. Zeinthaml, C. Competências Organizacionais e Vantagem Competitiva: o desafio da gerência intermediária. Rev. adm. empres. 2002; 42(1):3649.

5. Nina, R. Profissional da informação: o bibliotecário e suas representações das competências profissionais e pessoais para atuar em bibliotecas. Mestrado [s.l.] Universidade Federal de Santa Catarina, 2006.

6. Dutra, J.S. Gestão de Competências. São Paulo: Gente, 2001.

7. Rabaglio, M.O. Seleção por competências. São Paulo: Educador, 2001.

8. Chiavenato, I. Gestão de Pessoas. Tradução. Rio de Janeiro: Campus, 2010.

9. Levy-Leboyer, C. Gestión de lacompetencias. Barcelona: Gestión, 1997.

10. Magalhães, M. V.; Melo, S. C. de A. Morte E Luto: O Sofrimento do Profissional da Saúde. Psicologia e Saúde em Debate, Patos de Minas, v. 1, n. 1, p.6-8, abr. 20015.

Outubro, 2016:2(Edição Especial):28-40. 
11. Aguiar, M.A.F. Psicologia aplicada à administração. Tradução. São Paulo: Saraiva, 2006.

12. Fleury, M. Fleury, A. Construindo o conceito de competência. Rev. adm. contemp., 2001. 5(n. spe):183-196.

13. Le Boterf, G. De lacompétence. Essaisurunattracteurétrange, Paris: Les Editions d'organisation, 1994.

14. Bertolini, E.A.S. Competências: uma ferramenta para o desenvolvimento organizacional. Rev. téc. FIPEP, 2004, 4(1):73-84.

15. Saupe, R. Conceito de competência: validação por profissionais de saúde. Saúde Rev., Piracicaba, 2006, 8(18):31-37.

16. Bandura, A. Modificação do comportamento. Rio de Janeiro: Interamericana, 1979.

17. Rokeach, M.The nature of human values. Nova York: Free Press, 1973.

18. Schwartz, Y. Os ingredientes da competência: um exercício necessário para uma questão insolúvel. 1998. Educ. soc. 1998, 65:101-39.

19. Combinato, D.S.; Queiroz, M.S. Morte: uma visão psicossocial. Estudos de Psicologia. 2006; 11(2): 209216.

20. Kovacs, M.J. Educação para a Morte. Psicologia ciência e profissão [periódico da internet]. 2005; 25(3): 484497.

21. Aries, P. A História da Morte no Ocidente. Rio de Janeiro: Francisco Alves; 1977.

22. Angeramicamon, V.A.; Truchat, F.A.R.; knijnick, R.B.; Sebastiani, R.W. Psicologia Hospitalar: Teoria e Pratica. $2^{a}$ ed.São Paulo:Cengage Learning Edições Ltda.; 2010.

23. FREITAS, A.F.S.C.; Oliveira, S.A. Os impactos emocionais sofridos pelo profissional de psicologia frente à morte em contexto hospitalar. Umuarama. 2010: 18(4): 263273.

Outubro, 2016:2(Edição Especial):28-40. 
24. Bolzan, M.E.O. Estresse, Coping, Burnout, Sintomas Depressivos e Hardiness em Residentes Médicos. 2012; p.1132

25. Kovaleski, D.F.; Bressan, A. A síndrome de Burnout em profissionais de saúde. Saúde e Transformação Social. 2012:3(2) p.107-113.

26. Edmondson, A.; Bohmer, R. Organizational learning in health care. Health Forum Journal, Chicago, v. 44, n. 2, p. 32-35, 2001.

27. Abreu, K.L.; Stoll. I.; Ramos, L.S.; Baumgardt, R.A.; Kristensen, C.H. Estresse ocupacional e Síndrome de Burnout no exercício profissional da psicologia.

Psicologia: Ciência e Profissão. 2002: 22(2), p.2229.

28. Peduzzi M, Palma JJL. A equipe de Saúde. In: Schraiber LB, Nemes MIB, MendesGonçalves RB, organizadores. Saúde do adulto, programas e ações na unidade básica. São Paulo: Hucitec; 2000. p.234-50.

29. Pires D. Reestruturação produtiva e trabalho em saúde. 2,ed. São Paulo: Annablume; 2008.

30. Chiavenato, I. Introdução à teoria geral da administração. Tradução. Rio de Janeiro: Campus, 2000.

31. Maximiano, A. Introdução à Administração. São Paulo: Atlas, 1995.

Outubro, 2016:2(Edição Especial):28-40. 